\title{
Carotenoids, immune response and the expression of sexual ornaments in male greenfinches (Carduelis chloris)
}

\author{
Eduardo Aguilera \& Juan A. Amat
}

\begin{abstract}
Allocation trade-offs of carotenoids between their use in the immune system and production of sexual ornaments have been suggested as a proximate mechanism maintaining honesty of sexual signals. To test this idea, we experimentally examined whether carotenoid availability in the diet was related to variation in antibody response to novel antigens in male greenfinches (Carduelis chloris aurantiiventris), a species with extensive carotenoid-dependent plumage colouration. We also measured the cost of mounting a humoral response in terms of circulating carotenoids. Finally, we examined the relationship between plumage colour, immune response and circulating carotenoids. We found that males with carotenoid-supplemented diets showed stronger antibody response than non-supplemented birds. We also found that activation of the immune system significantly reduced circulating carotenoids (24.9\% lower in immune-challenged birds than in control birds). Finally, intensity (chroma) of ventral plumage colouration of males, a character directly related to concentration of total carotenoids in feathers, was negatively correlated with the immune response and circulating carotenoids in winter. These results support the idea that carotenoids are a limiting resource and that males trade ornamental colouration against immune response.
\end{abstract}

Keywords Sexual selection · Immune response · Carotenoids · Plumage colour

E. Aguilera $(\star) \cdot J$. A. Amat Department of Evolutionary Biology, Estación Biológica de Doñana, CSIC, Apartado 1053, 41080 Seville, Spain e-mail: aguilera@ebd.csic.es
Introduction

In many animal species, males that display more conspicuous ornaments are preferred by females as mates (Andersson 1994). This finding raises two important questions that have been the focus of studies on sexual selection in the last decades. First, what does a female gain by choosing a more ornamented male and, second, what limits the expression of sexual ornaments. Hamilton and Zuk (1982) proposed that animals choose mates for genetic parasite resistance on the basis of characters whose full expression is dependent on condition. Because parasites reduce health and vigour of their hosts, only those males resistant to prevailing parasites could develop the larger or more conspicuous ornaments. A physiological mechanism linking parasites and sexual ornaments is based on trade-offs between the immune system and production of ornaments (Folstad and Karter 1992). According to this hypothesis, both ornaments and the immune system compete for the same limited resources such as energy or metabolites (Wedekind 1992; Wedekind and Folstad 1994). More ornamented males are thus indicating that they either (a) can obtain more of those resources, in which case, production of ornaments do not compromise immune defences or (b) that they can divert resources from the immune system to ornamentation without serious risks to their health because of their superior genetic resistance to parasites (Westneat and Birkhead 1998).

Carotenoids are biological pigments responsible for red, orange and yellow colouration of integuments in birds and fishes. Male birds with carotenoid-dependent plumage colours are often more colourful than females (Gray 1996; Olson and Owens 1998) and, for a number of species, females prefer to mate with males with a more intense colour (reviewed in Hill 1999a). In addition to its function as pigments in ornamental traits, carotenoids are powerful antioxidants which play a key role in many vital processes 
including the immune system (Bendich 1989; Chew 1993). Owing to their dual role in ornamentation and immunological defences, carotenoids have become prominent subjects in studies of sexual selection, particularly as potential proximate factors mediating the trade-off between the immune system and sexual ornaments (Lozano 1994; von Schantz et al. 1999). The carotenoid-immunocompetence trade-off hypothesis (Lozano 1994) is based on the assumptions that immune defences of animals with carotenoid-dependent ornaments are limited by carotenoid availability, an issue currently debated (Hill 1999b; Lozano 2001), and that activation of the immune system reduces the amount of carotenoids available for ornamentation. Recent studies in birds have demonstrated that supplementation of the diet with carotenoids improves the immune response (Blount et al. 2003; McGraw and Ardia 2003; but see Navara and Hill 2003). Activation of the immune system reduces the intensity of bill colouration in blackbirds (Turdus merula; Faivre et al. 2003a) and zebra finches (Taeniopygia guttata; Blount et al. 2003; McGraw and Ardia 2003; Alonso-Alvarez et al. 2004) in agreement with the idea that carotenoids are traded off against both the immune system and sexual signalling.

In this study, we investigated the relationships between carotenoids, immune defences and plumage colouration in male greenfinches (Carduelis chloris aurantiiventris). Males in this species have a bright yellow breast and belly plumage, while females have a duller plumage on the breast and frequently lack the yellow colouration of the belly (Cramp and Perrins 1994). Carotenoid pigments have been shown to be responsible for the yellow colouration in this species (Stradi et al. 1995; Saks et al. 2003a). In addition, a previous study has shown that more brightly coloured males are preferred by females as mates (Eley 1991). By experimentally manipulating carotenoid content in the diet of captive male greenfinches and inoculating two types of antigens, we tested whether humoral immune response is limited by carotenoid availability in a species with extensive carotenoid-dependent plumage colouration. We also estimated the cost of activation of the immune system in terms of carotenoids by comparing changes in circulating carotenoid levels of immune challenged males in relation to control males. Finally, we examined the relationship between plumage colour of the males and the strength of the humoral immune response and carotenoid concentration in blood.

Materials and methods

\section{General}

We captured under license 74 first year male greenfinches with mist nets between 16 October and 1 November 2000 near Seville (SW Spain) just after they had completed the moult in the wild. After capture, birds were weighed and bill, tarsus and wing lengths measured. We also measured the colour of plumage at capture using a Minolta CR-200 colorimeter (Figuerola et al. 1999), which measures colour in the visible spectrum region (400-700 nm). Colour was measured twice in each of two areas of the ventral region (breast and belly) and expressed in the CIE variables lightness, chroma and hue. Lightness, measured in a scale of 0 (black) to 100 (white), is related to the amount of light reflected by the measured surface. Hue, measured in degrees $\left(0^{\circ}\right.$ corresponds with pure red, $90^{\circ}$ with yellow, $180^{\circ}$ with green and $270^{\circ}$ blue), is related to the maximum wavelength of the spectra and chroma corresponds to saturation or purity of the colour in a scale of 0 (grey) to 100 (pure colour).

To examine the relationship between immunocompetence and plumage colour, we obtained a measure of plumage colour of each bird by averaging, for each colour component, the two measures of each area and then calculating the mean for the ventral region. The repeatability of the measure of ventral colour was high for its three components (intraclass correlation coefficients, 0.70-0.77, $\mathrm{n}=74$, all $\mathrm{p}<0.0001$; calculated for the body average of two repeated measures per individual). A previous study has shown that chroma and, in a lesser extension, hue are good predictors of the carotenoid content of tail feathers in this species (Saks et al. 2003a. Note that colour in this study was also measured in the visible region of the spectrum). For the purposes of this study, only chroma and lightness were analysed (chroma and hue were negatively correlated: $r=-0.76, \quad p<0.0001$; lightness was neither significantly correlated with chroma: $r=0.17, p>0.05$, nor with hue: $r=$ $0.17, \mathrm{p}>0.05 ; \mathrm{n}=74$ in the three analyses). Birds were housed in three outdoor aviaries $(3 \times 3 \times 2 \mathrm{~m}$ high) until the start of experiments. Food, consisting of a commercial mixture of seeds for canary plus sunflower seeds (see Amat et al. 2007 for details on the diet), and water were provided ad libitum.

\section{Manipulation of carotenoid availability}

We performed a pilot study to assess the effects of supplementing the diet with different concentrations of carotenoids on plasma levels of carotenoids in greenfinches. We used a commercial extract of saponified xanthophylls (about $5 \%$ of zeaxanthin and $88 \%$ of lutein; Chromophil-Aqua, Bioquimex Europe, Madrid). On 11 November, 20 first year males were housed in individual cages and randomly assigned to one of four groups (five individuals per group) according to concentration of xanthophylls in the birds' water: control, water not treated; low, $0.55 \mu \mathrm{g}$ of xanthophylls per millilitre of water; 
medium, $1.1 \mu \mathrm{g}$ of xanthophylls per millilitre of water; high, $5.5 \mu \mathrm{g}$ of xanthophylls per millilitre of water. Blood samples were taken from each bird every 4 days, starting just before we supplemented birds with xanthophylls (day 0) and ending on day 16. Blood was centrifuged at 3,000 rpm during $10 \mathrm{~min}$ and plasma separated and kept at $-20^{\circ} \mathrm{C}$ until analysis (see below). These birds were not used in the experiment to estimate the costs of mounting an immune response and were released at the capture sites just after the pilot study.

Xanthophylls supplementation significantly affected changes in carotenoid plasma concentration from day 0 to day 16 (Fig. 1; analysis of variance (ANOVA) for repeated measures, interaction between groups and temporal changes in plasma carotenoids, $\mathrm{F}_{12,64}=2.23, \mathrm{p}=0.02$ ). Mean levels of circulating carotenoids for the four groups increased from day 0 to day 16 , the slopes being proportional to the concentration of xanthophylls in the birds' water. For the study of the effects of carotenoid availability on the intensity of humoral immune response, we chose xanthophylls concentration of the high supplemented group, as it was the only group whose $95 \%$ confidence interval of its mean did not include the mean of the control group.

\section{Experimental design}

On 4 December, 44 birds were randomly divided into four groups (11 birds per group) which were housed in different aviaries $(3 \times 3 \times 2 \mathrm{~m}$ high). We supplemented the standard seed diet of two groups with $5.5 \mu \mathrm{g} / \mathrm{ml}$ of xanthophylls (see above for justification of this concentration) dissolved in drinking water. The other two groups received the same standard seed diet and not treated water. On 11 December,

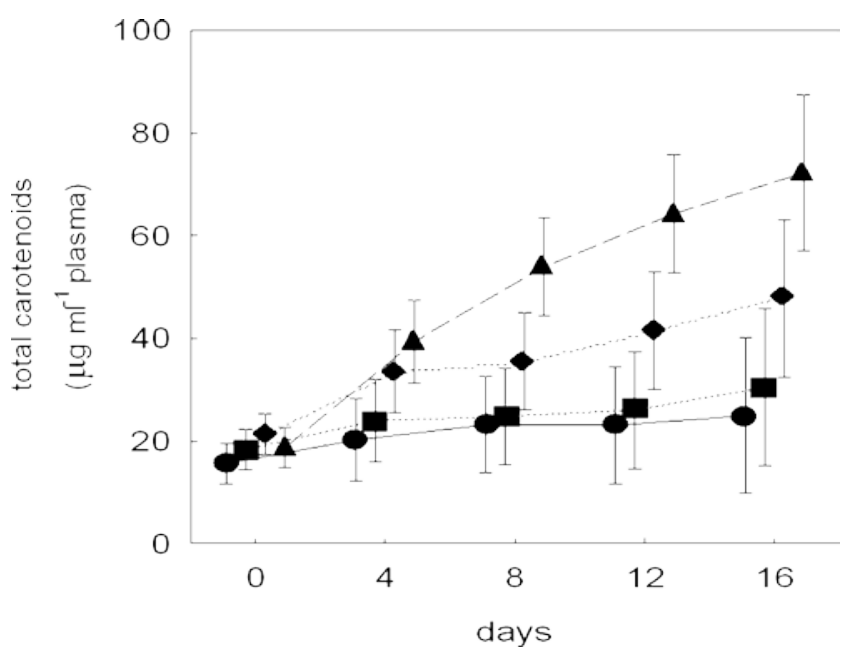

Fig. 1 Effects of different concentration of carotenoids in the drinking water on changes in total plasma carotenoids (means \pm SE are provided; $\mathrm{n}=5$ birds in each group. Circles: control; squares: $0.55 \mu \mathrm{g} / \mathrm{ml}$; rhombuses: $1.1 \mu \mathrm{g} / \mathrm{ml}$; triangles: $5.5 \mu \mathrm{g} / \mathrm{ml}$ ) birds were weighed with a portable electronic balance to the nearest $0.1 \mathrm{~g}$ and were housed in individual cages $(30 \times 20 \times$ $30 \mathrm{~cm}$ high) inside an outdoor aviary. Because we performed a parallel study to measure energetic and other physiological costs of mounting an immune response (Amat et al. 2007), only those individuals that had not lost any flight feather during captivity $(\mathrm{n}=30)$ were included in the study. Diet of birds in individual cages was the same as in aviaries. On 14 December, 10 days after the start of carotenoid supplementation, we weighed the birds and took a blood sample from the brachial vein to measure plasma concentration of carotenoids at the start of immune challenge. After blood extraction, we randomly assigned half of the carotenoids-supplemented birds and half of the non-supplemented birds to one of two groups according to whether they were injected with antigens or with phosphate buffered saline (PBS). We combined two types of antigens, sheep red blood cells (SRBC; R3378 Sigma-Aldrich, St. Louis) and Brucella abortus agglutination concentrate (BA; BF502 Bifa-kit SL, Madrid) to challenge the immune system of birds. SRBC antigens stimulate T-dependent humoral response, while BA antigens induce the proliferation of B cells for antibody production (Higgins 1996). This combination of antigens has been used before to measure the two components of the avian humoral response in poultry (e.g. Li et al. 2000) and wild birds (e.g. Birkhead et al. 1998). We administered birds from the immunechallenged group an intramuscular injection of $25 \mu \mathrm{l}$ of BA and, via intraperitoneal, an injection of $2 \%$ SRBC suspended in $100 \mu \mathrm{l}$ of PBS. Birds of the control group were administered equivalent volumes of PBS, both intramuscular and intraperitoneal, as immune-challenged birds. On 20 December (6 days after injection of either PBS or antigens), we collected a second blood sample from these birds in microcapillary tubes. Blood was centrifuged during $10 \mathrm{~min}$ at 3,000 rpm, and plasma was separated and kept at $-20^{\circ} \mathrm{C}$ until carotenoid concentration and antibody titres were measured.

Antibody measures

We used haemoagglutination assays in 96-well micro-plates to measure antibody titres to SRBC (Wegmann and Smithies 1966). Briefly, $20 \mu \mathrm{l}$ of plasma were added to $20 \mu \mathrm{l}$ of PBS in the first well of a plate and serially diluted in PBS $(1 / 2,1 / 4,1 / 8$, etc.). We then added $20 \mu \mathrm{l}$ of a $2 \%$ suspension of SRBC to each well. Plates were kept at ambient temperature and examined for agglutination $2 \mathrm{~h}$ after they were prepared. Antibody titres to BA were measured by agglutination assays (Munns and Lamont 1991). We followed the same protocols as for haemoagglutination assays, but SRBC was substituted by BA agglutination concentrate, and plates were examined for 
agglutination after $24 \mathrm{~h}$ according to recommendations by the manufacturer. Antibody responses to each antigen were estimated as the $\log _{2}$ of the reciprocal of the higher dilution which showed visible agglutination.

\section{Determination of plasma carotenoids concentration}

The concentration of total plasma carotenoids was measured with a spectrophotometer following Allen (1987) (see Tella et al. 1998 for an evaluation of this method). We diluted $15 \mu \mathrm{l}$ of plasma in $285 \mu \mathrm{l}$ of $100 \%$ acetone (dilution $1: 20)$. After mixing the solution with a vortex, the flocculant protein was precipitated by centrifugation (10.000 rpm during $10 \mathrm{~min}$ ). The absorbance of the supernatant was measured in the spectrophotometer at $476 \mathrm{~nm}$, and the concentration of total carotenoids in plasma was calculated with the formula:

\section{C $1 / 4 \mathrm{~A}_{476 n m} \times \mathrm{D} \times \mathrm{E}$}

where $\mathrm{C}$ is the concentration $(\mu \mathrm{g} / \mathrm{ml})$ of total carotenoids in plasma, $A_{476} \mathrm{~nm}$ is the absorption at $476 \mathrm{~nm}$ of the sample, $\mathrm{D}$ is the factor of dilution (20 in this study) and E, the absorption coefficient of carotenoids in the same solvent, was derived from a standard curve of lutein dissolved in acetone. Spectrophotometric estimates of plasma total carotenoids in this species were highly correlated with those from high-performance liquid chromatography analyses $(\mathrm{r}=0.98, \mathrm{n}=24, \mathrm{p}<0.0001$; Garrido and Aguilera, unpublished data).

\section{Statistical analyses}

As antibody titers, a variable measured in a logarithmic scale, differed from a normal distribution, nonparametric statistics were used in all analyses that included this variable (Mann-Whitney's U test and Spearman rank correlation). We ran parametric statistical tests in the analyses of the other dependent variables (lightness, chroma and carotenoid plasma concentration), as their distributions met the assumptions of normality (KolmogorovSmirnov tests) and homoscedasticity (Leven's tests). To test for an effect of dietary carotenoid treatment on carotenoid plasma concentration at the start of the immune challenge experiment, we used a nested ANOVA with carotenoid treatment and aviary identity as factors and aviary identity nested within carotenoid treatment. We used an analysis of covariance (ANCOVA) to test for the effects of carotenoid supplementation and immune challenge on plasma carotenoid concentration at day 6, including concentration at day 0 as a covariate. To see if carotenoid plasma concentration was related to plumage variables, we com-

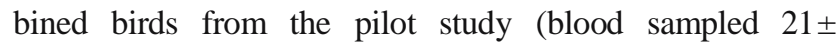
1.2 days after capture and just before the carotenoid supplementation experiment) and those from the carotenoid supplementation study (blood sampled $45 \pm 1.4$ days after capture, i.e. 10 days after the carotenoid supplementation experiment and just before the immune challenge). We used an ANCOVA with plasma carotenoids as the response variable and the two colour parameters (lightness, chroma) as covariates. To control for the effects of experimental conditions on circulating carotenoids, we included in the ANCOVA a factor (experiment) with three categories (pilot birds, non-supplemented birds and supplemented birds; combining pilot birds with non-supplemented birds gives similar results). Analyses were conducted with Statistica 6.0 (StatSoft, 1984-2001, Tulsa, OK, USA). All significance levels are two tailed with the critical $\mathrm{P}$ value for significance set at 0.05. ANOVAs and ANCOVAs were based on type III SS (sums of squares).

\section{Results}

Effects of carotenoids supplementation on the intensity of the immune response

Randomly assigned birds from the control and carotenoidsupplemented groups did not differ significantly in any of the plumage colour variables measured at capture (Lightness: $\mathrm{F}_{1,28}=0.03, \mathrm{P}=0.87$; Chroma: $\mathrm{F}_{1,28}=0.94, \mathrm{P}=0.34$ ), neither in body mass at capture or during the immune challenge (all $\mathrm{P}>0.14$; Amat et al. 2007). Ten days after the carotenoid treatment, at the start of the immune-challenge experiment, supplemented birds showed higher concentration of plasma carotenoids than control birds (carotenoidsupplemented: LS mean \pm SE, $21.02 \pm 3.14 \mu \mathrm{g} / \mathrm{ml}, \mathrm{n}=18$; control: LS mean \pm SE, $10.51 \pm 1.93 \mu \mathrm{g} / \mathrm{ml}, \mathrm{n}=12 ; \mathrm{F}_{1,28}=$ 6.34, $\mathrm{p}=0.02$; nested ANOVA: carotenoid treatment: $\mathrm{F}_{1,26}=$ 7.71, $\mathrm{P}=0.01$; aviary: $\mathrm{F}_{2,26}=1.16, \mathrm{P}=0.33$ ), indicating that our carotenoid treatment had an effect on circulating carotenoids at the time birds were immune-challenged. In addition, the range of total plasma carotenoids at the end of the experiment $(5.2-76.8 \mu \mathrm{g} / \mathrm{ml})$ was within the natural range of the wild population (5.0-91.4 $\mu \mathrm{g} / \mathrm{ml} ; \mathrm{n}=162$ first year males; Aguilera, unpublished data).

For unknown reasons, none of the immune-challenged birds showed haemoagglutination response to SRBC. Agglutination to BA was observed in 12 out of 16 birds injected with antigens, while none of the birds from the control group (injected with PBS) showed antibody responses to BA. Supplemented birds exhibited higher titres of antibodies to BA than non-supplemented birds (Mann-Whitney U test, z=2.06, $\mathrm{P}=0.04$; Fig. 2). 


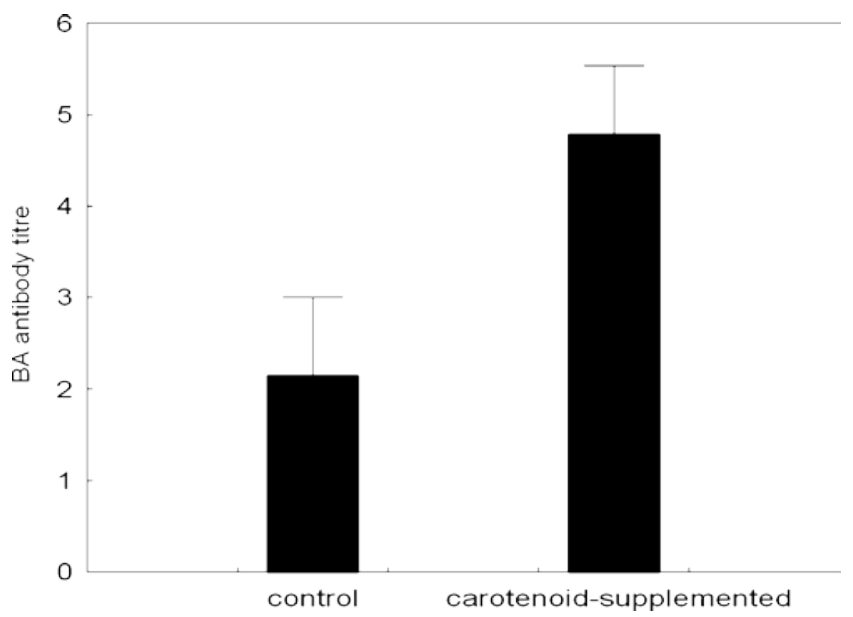

Fig. 2 Means and SE of Brucella abortus antibody titers for the control $(n=7)$ and the carotenoid-supplemented $(n=9)$ groups

Carotenoid costs of mounting an immune response

After controlling for values at day 0 , carotenoid concentration at day 6 of the immune challenge experiment was not affected by carotenoid treatment (Table 1, Fig. 3). Immune treatment had a significant effect on circulating carotenoids. After 6 days of the immune treatment, antigen-injected birds showed lower plasma carotenoid levels than PBSinjected birds (Table 1, Fig. 3). The interaction between immune treatment and carotenoid supplementation was non-significant (Table 1), indicating that the effect of immune activation on plasma carotenoid concentration was independent of carotenoid availability. Immunechallenged birds had a concentration of plasma carotenoids on day 6 that was $24.9 \%$ lower than that of PBS-injected birds (antigen injected birds: LS mean \pm SE, $19.3 \pm 1.7 \mu \mathrm{g} / \mathrm{ml}$; PBS-injected birds: LS mean \pm SE, $25.7 \pm 2.1 \mu \mathrm{g} / \mathrm{ml}$; statistics according to the ANCOVA model in Table 1).

Plumage colour, immune response and plasma carotenoids

Antibody titres to BA significantly and negatively correlated with plumage chroma (Spearman rank order correlation

Table 1 Results of an ANCOVA with concentration of total plasma carotenoids at day 6 of the immune challenge experiment as the response variable, carotenoid treatment and immunological treatment as factors and concentration of total plasma carotenoids at day 0 as covariate

\begin{tabular}{lllll}
\hline Source & MS & F & df & P \\
\hline $\begin{array}{l}\text { Plasma carotenoid } \\
\text { concentration at day } 0\end{array}$ & $18,312.6$ & 331.5 & 1,26 & $<0.001$ \\
Carotenoid treatment & 51.1 & 0.9 & 1,26 & 0.345 \\
$\begin{array}{l}\text { Immunological treatment } \\
\text { Carotenoid treatment } \times\end{array}$ & 283.2 & 5.1 & 1,26 & 0.032 \\
$\quad$ immunological treatment & & 0.1 & 1,26 & 0.819 \\
\hline
\end{tabular}

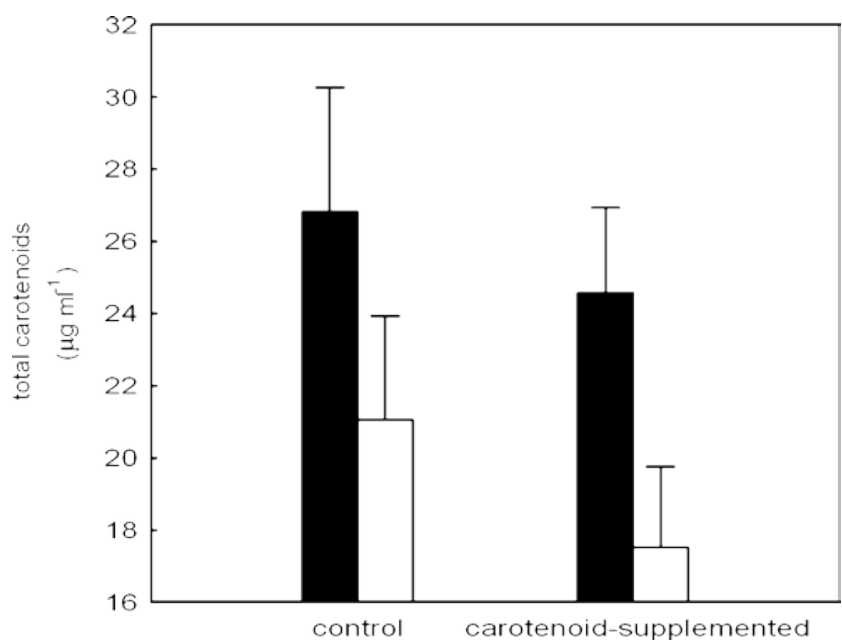

Fig. 3 Plasma carotenoid concentration at day 6 of the immune challenge for the different experimental groups. Filled columns: PBS-injected birds $(n=5$ and $n=9$ in the control and carotenoid-supplemented groups, respectively); open columns: immune-challenged birds ( $n=7$ and $n=9$ in the control and carotenoid-supplemented groups, respectively). Values are LS means+SE according to the ANCOVA model in Table 1

$r_{s}=-0.71, n=16, P=0.004$; Fig. 4a). No significant association between immune response and plumage lightness was observed $\left(r_{s}=0.20, n=16, P=0.47\right.$; Fig. 4b). Plumage chroma was the only colour variable that, after controlling for differences among experimental groups in total plasma carotenoid concentration, significantly and negatively correlated with concentration of total plasma carotenoids (Table 2).

\section{Discussion}

This study demonstrated that by supplementing a standard seed diet with carotenoids, male greenfinches increased their carotenoid plasma concentration and their humoral immune response to Brucella abortus antigens. Although we were unable to detect an antibody response to SRBC in our greenfinches, in another study with this species, individuals exhibited a humoral response to the same antigen (Saks et al. 2003b). The different results may reflect differences in SRBC concentrations and/or in the route of inoculation between both studies (see Kreukniet et al. 1992; Boa-Amponsem et al. 2001). Regardless of the cause responsible for the failure to detect the response to SRBC, results concerning to BA response support the view that the immune response of birds with extensive carotenoidbased ornaments is limited by carotenoid availability and, thus, that carotenoids can mediate the trade-off between ornamentation and immune function (Lozano 1994, 2001; von Schantz et al. 1999). These results are consistent with three recent experimental studies, but contradicts another 

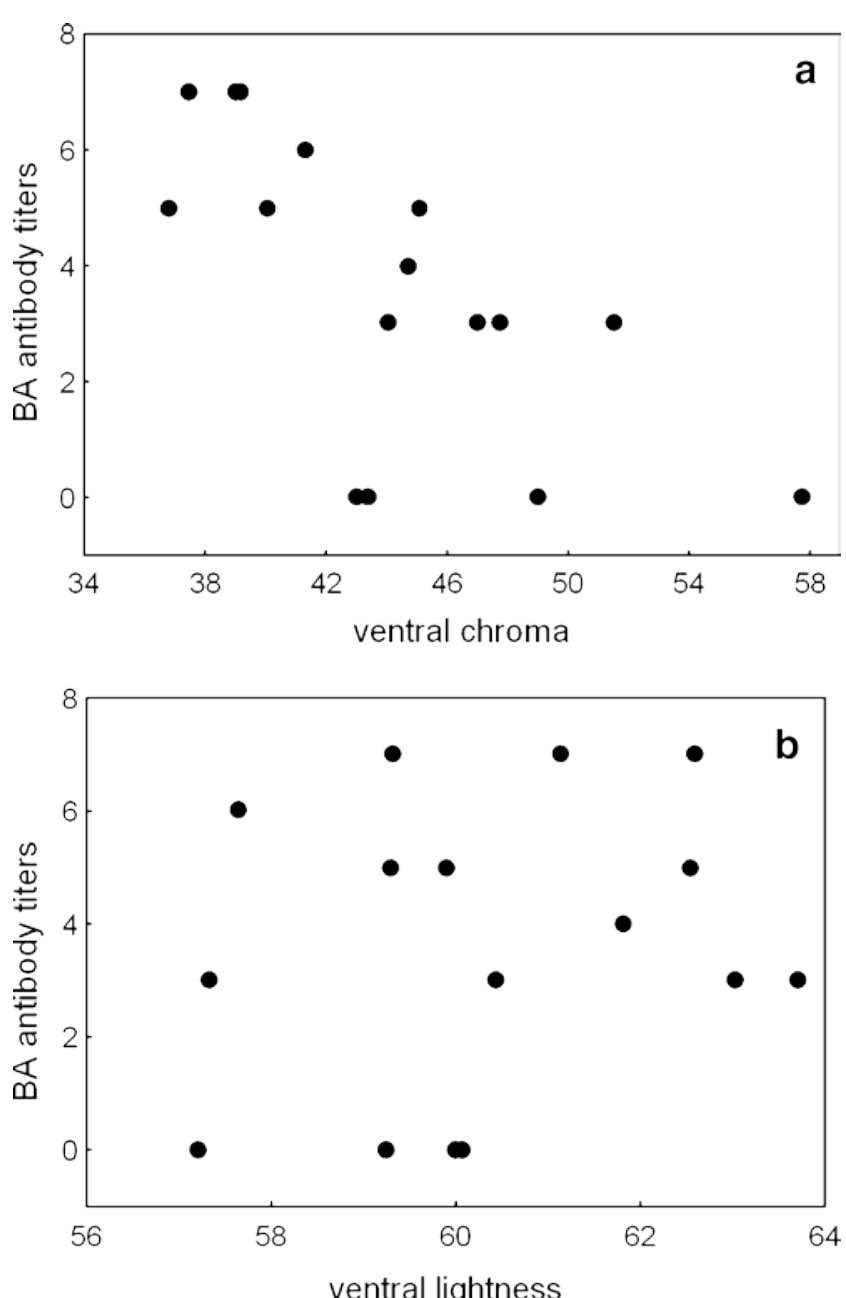

Fig. 4 Relationship between antibody response to B. abortus and a ventral plumage chroma and $b$ ventral plumage lightness

one. Increased cell-mediated immunity as a result of supplementation of the diet with carotenoids was found in moorhen (Gallinula chloropus) chicks (Fenoglio et al. 2002) and male zebra finches (T. guttata; Blount et al. 2003; McGraw and Ardia 2003). Supplemented birds of this species also show an increase of humoral immune response to SRBC (McGraw and Ardia 2003). On the contrary, a carotenoid-supplementation study in American goldfinches (Carduelis tristis) did not find any significant effect of concentration of carotenoids in the diet on cellmediated immunity nor on humoral response to an injection of SRBC (Navara and Hill 2003).

The carotenoid-immunocompetence trade-off hypothesis posits that mounting an immune response has costs in terms of a reduction in the amount of carotenoids available for ornamentation. Indeed, we showed that immune-challenged birds reduced their plasma carotenoid levels by $25 \%$ comnared to control hirds. This reduction is lower than that fnund in rhirkens for a Corridian rhallenoe $\mathbf{7 5 - 8 9 \%}$ reductions. Allen 1992). but similar to that induced bv lipopolysaccharide and interleukin-1 (about 30\% reductions, Koutsos et al. 2003; see also Alonso-Alvarez et al. 2004). Overall, these studies indicate that both infectious pathogens and relatively benign antigens can dramatically depress circulating carotenoid levels in birds. Besides, we have shown that changes in circulating carotenoids caused by an immune challenge was independent of carotenoid availability in the diet, a result also found by Alonso et al. (2004). This suggests a differential cost for males, in terms of ornaments, derived from mounting an immune response because only males with high initial reserves of carotenoids could express welldeveloped ornaments when immune-challenged.

We found that duller males, i.e. those with lower values of chroma and, consequently, more female-like birds (male/ female ratio: chroma $=2.0$, hue $=1.0$, lightness $=0.96$; males, $n=212$, females, $n=167$; Aguilera, unpublished data), respond stronger to $\mathrm{BA}$ and have higher concentration of plasma carotenoids. Because we made comparisons in winter, outside the moult period, we have not directly tested the existence of a trade-off between immune defences and ornaments when these are developing. However, as chroma is a good predictor of feather carotenoid content in this species (Saks et al. 2003a), these results could suggest that males allocated more carotenoids to feather colouration during moult at the expense of their reserves of carotenoids to respond to immune challenges during winter, supporting, in this case, the carotenoidimmunocompetence trade-off hypothesis. Alternatively, if more colourful males are dominant over drabber ones, as demonstrated for this species (Maynard Smith and Harper 1988), and dominance is related to testosterone levels, we would expect lower immune response in dominant birds (i.e. the brighter males). This may result either as a direct consequence of the immunosuppressive effects of testosterone (Folstad and Karter 1992; Evans et al. 2000) or, indirectly, by the effect of testosterone on the increase of oxidative stressing activities such as locomotion, vocalisation and aggression (Wingfield et al. 1990; Senar et al. 2000; Lynn et al. 2000). This would lead to a greater demand of antioxidant compounds such as carotenoids and, consequently, to a lower immune response.

Under this scenario, females could benefit from mating with more colourful males not because these are more

Table 2 ANCOVA of plasma carotenoid concentration and plumage colour variables, controlling for experiment [three groups: pilot birds $(n=20)$, carotenoid-supplemented birds $(n=18)$ and control birds $(n=12)$; see "Materials and methods" for more details]

\begin{tabular}{lrlll}
\hline Source & $\mathrm{F}$ & Beta (SE) & $\mathrm{df}$ & $\mathrm{P}$ \\
\hline Experiment & 6.84 & & 2,45 & 0.002 \\
Lightness & 0.15 & $0.05(0.12)$ & 1,45 & 0.696 \\
Chroma & 11.34 & $-0.41(0.12)$ & 1,45 & 0.002
\end{tabular}


efficient foragers or the most immunocompetent ones but because they have a genome more adapted to prevailing parasites (Hamilton and Zuk 1982), and thus, can draw carotenoids from immunological defences without serious risks for their health (Westneat and Birkhead 1998; von Schantz et al. 1999). The negative correlation between ornamental expression and immune defences is consistent with the general trend found in vertebrates (reviewed in Møller et al. 1999, 2000) for a variety of sexual ornaments and immunological measures. To our knowledge, only two studies have examined the relationship between carotenoiddependent plumage colour and the response to an immunological challenge. Navara and Hill (2003) did not find any significant relationship between intensity of colour and cell-mediated or humoral immune response in male goldfinches (C. tristis) during moult. Our results apparently contradict a previous study on greenfinches (Saks et al. 2003b) which found a positive relationship between intensity of the humoral response to SRBC and the "yellow brightness" of the breast feathers of males in winter. There are several differences between the two studies on greenfinches that could explain this contradiction. First, the variable of colour used in Saks et al. 2003b (the sum of reflectances between 550 and $625 \mathrm{~nm}$ ) is different from those used in this study (see Endler 1990 for details). This measure was in fact highly correlated with total brightness ( $r=0.97$; Saks et al. 2003b), a component of colour not related to the concentration of carotenoids in feathers (Saks et al. 2003a). Indeed, we cannot rule out the possibility that different components of plumage colour in greenfinches may signal different aspects of the males' quality (Møller and Pomiankowski 1993). Another possible explanation is that the positive correlation found in Saks et al. (2003b) was between plumage colour and T-dependent humoral response (antibodies against SRBC), while the negative correlation found in this study was between plumage colour and T-independent humoral response (antibodies against BA). Several studies have shown opposite relations between the expression of an ornament and different measures of immune function. For example, Faivre et al. (2003b) found that the intensity of bill colour of male blackbirds ( $T$. merula) was positively correlated to cell-mediated immune response, but was negatively correlated to antibody titres against SRBC (see also Møller and Petrie 2002). In the case of greenfinches, plumage colour was not related to cellmediated immune response (Saks et al. 2003b).

Overall, our results showed a stronger immune response of carotenoid-supplemented birds, a significant reduction of circulating carotenoids in immune-challenged birds and a lower immune response of brighter males, which support the ideas that carotenoids are a limiting resource and that males may trade ornamental colouration against immune response.
Acknowledgements We thank Manolo Vázquez, Rocío Ruiz, María López and Nico Varo for assistance with trapping and taking care of birds, María José Torres for laboratory training and Tomás Redondo, Jordi Figuerola, Kevin McGraw and three anonymous referees for constructive criticisms on an earlier version of the manuscript. Financial support was provided by the Spanish DGESIC (project PB98-0494-C02-01).

\section{References}

Allen PT (1987) Effect of Eimeria acervulina infection on chick (Gallus domesticus) high density lipoprotein composition. Comp Biochem Physiol 87B:313-319

Allen PT (1992) Effect of coccidiosis on the distribution of dietary lutein in the chick. Poult Sci 71:1457-1463

Alonso-Alvarez C, Bertrand S, Devevey G, Gaillard M, Prost J, Faivre B, Sorci G (2004) An experimental test of the dose-dependent effect of carotenoids and immune activation on sexual signals and antioxidant activity. Am Nat 164:651-659

Amat JA, Aguilera E, Visser GH (2007) Energetic and developmental costs of mounting an immune response in greenfinches (Carduelis chloris). Ecol Res 22:282-287

Andersson M (1994) Sexual selection. Princeton University Press, Princeton

Bendich A (1989) Carotenoids and the immune response. J Nutr 119:112-115

Birkhead TR, Fletcher F, Pellat EJ (1998) Sexual selection in the zebra finch Taeniopygia guttata: condition, sex traits and immune capacity. Behav Ecol Sociobiol 44:179-191

Blount JD, Metcalfe NB, Birkhead TR, Surai PF (2003) Carotenoid modulation of immune function and sexual attractiveness in zebra finch. Science 300:125-127

Boa-Amponsem K, Price SHE, Dunnington EA, Siegel PB (2001) Effect of route of inoculation on humoral immune response of White Leghorn chickens selected for high or low antibody response to sheep red blood cells. Poultry Sci 80:1073-1078

Chew BP (1993) Role of carotenoids in the immune response. J Dairy Sci 76:2804-2811

Cramp S, Perrins CM (1994) The birds of Western Palaearctic, vol VII. Oxford University Press, Oxford

Eley C (1991) Status signalling in the western green finch (Carduelis chloris). Ph.D. thesis, University of Sussex, Brighton, UK

Endler JA (1990) On the measurement and classification of colour in studies of animal colour patterns. Biol J Linn Soc 41:315-352

Evans MR, Goldsmith AR, Norris SRA (2000) The effects of testosterone on antibody production and plumage coloration in male house sparrows (Passer domesticus). Behav Ecol Sociobiol 47:156-163

Faivre B, Gregorie A, Preault M, Cézilly F, Sorci G (2003a) Immune activation rapidly mirrored in a secondary sexual trait. Science 300:103

Faivre B, Preault M, Salvadori F, Thery M, Gaillard M, Cézilly F (2003b) Bill colour and immunocompetence in the European blackbird. Anim Behav 65:1125-1131

Fenoglio S, Cucco M, Malacarne G (2002) The effect of a carotenoidrich diet on immunocompetence and behavioural performance in moorhen chicks. Ethol Ecol Evol 14:149-156

Figuerola J, Senar JC, Pascual J (1999) The use of colorimeters on free-living birds: sex, age and locality differences in blue tits (Parus caeruleus) coloration. Ardea 87:269-275

Folstad I, Karter AJ (1992) Parasites, bright males and the immunocompetence handicap. Am Nat 139:603-622

Gray DA (1996) Carotenoids and sexual dichromatism in North American passerine birds. Am Nat 148:453-480 
Hamilton WD, Zuk M (1982) Heritable true fitness and bright birds: a role for parasites? Science 218:384-387

Higgins DA (1996) Comparative immunology of avian species. In: Davison TF, Morris TR, Payne LN (eds) Poultry immunology. Carfax, Abingdon, pp 149-205

Hill GE (1999a) Mate choice, male quality, and carotenoid-based plumage colouration. In: Adams N, Slowtow R (eds) Proceedings of the 22nd International Ornithological Congress. Durban, pp 1654-1668

Hill GE (1999b) Is there an immunological cost to carotenoid-based ornamental coloration? Am Nat 154:589-595

Koutsos EA, Calvert CC, Klasing KC (2003) The effects of an acute phase response on tissue carotenoid levels of growing chickens (Gallus gallus domesticus). Comp Biochem Physiol 135A:635646

Kreukniet MB, van der Zijpp AJ, Nieuwland MGB (1992) Effects of route of immunization, adjuvant and unrelated antigens on the humoral immune response in lines of chickens selected for antibody production against sheep erythrocytes. Vet Immunol Immunopathol 33:115-127

Li Z, Nestor KE, Saif YM, Anderson JW (2000) Antibody responses to sheep red blood cell and Brucella abortus antigens in a turkey line selected for increased body weight and its random bred control. Poultry Sci 79:804-809

Lozano GA (1994) Carotenoids, parasites, and sexual selection. Oikos 70:309-311

Lozano GA (2001) Carotenoids, immunity, and sexual selection: comparing apples and oranges? Am Nat 158:200-203

Lynn SE, Houtman AM, Weathers WW, Ketterson ED, Val Nolan JR (2000) Testosterone increases activity but not daily energy expenditure in captive male dark-eyed juncos (Junco hyemalis). Anim Behav 60:581-587

Maynard Smith J, Harper DGC (1988) The evolution of aggression: can selection generate variability? Philos Trans R Soc Lond B Biol Sci 319:557-570

McGraw KJ, Ardia DR (2003) Carotenoids, immunocompetence, and the information content of sexual colors: an experimental test. Am Nat 162:704-712

Møller AP, Petrie M (2002) Condition dependence, multiple sexual signals, and immunocompetence in peacocks. Behav Ecol 13:248-253

Møller AP, Pomiankowski A (1993) Why have birds got multiple sexual ornaments? Behav Ecol Sociobiol 32:167-176

Møller AP, Christe P, Lux E (1999) Parasitism, host immune function, and sexual selection. Q Rev Biol 74:3-20
Møller AP, Biard C, Blount JD, Houston DC, Ninni P, Saino N, Surai PF (2000) Carotenoid-dependent signals: indicators of foraging efficiency, immunocompetence or detoxification ability? Avian Poult Biol Rev 11:137-159

Munns PL, Lamont SJ (1991) Effects of age and immunization interval on anamnestic response to T-cell-dependent and T-cellindependent antigens in chickens. Poultry Sci 70:2371-2374

Navara KJ, Hill GE (2003) Dietary carotenoid pigments and immune function in a songbird with extensive carotenoid-based plumage coloration. Behav Ecol 14:909-916

Olson VA, Owens IPF (1998) Costly sexual signals: are carotenoids rare, risky or required. Trends Ecol Evol 13:510-514

Saks L, McGraw K, Hõrak P (2003a) How feather colour reflects its carotenoid content. Funct Ecol 17:555-561

Saks L, Ots I, Hõrak P (2003b) Carotenoid-based plumage coloration of male greenfinches reflects health and immunocompetence. Oecologia 134:301-307

Senar JC, Polo V, Uribe F, Camerino M (2000) Status signalling, metabolic rate and body mass in the siskin: the costs of being subordinate. Anim Behav 59:103-110

Stradi R, Celentano G, Rossi E, Rovati G, Pastore M (1995) Carotenoids in bird plumage. I. The carotenoid pattern in a series of Palearctic Carduelinae. Comp Biochem Physiol 110B:131-143

Tella JL, Negro JJ, Rodríguez-Estrella R, Blanco G, Forero MG, Blázquez MC, Hiraldo F (1998) A comparison of spectrophotometry and color charts for evaluating total plasma carotenoids in wild birds. Physiol Zool 71:708-711

von Schantz T, Bensch S, Grahn M, Hasselquist D, Wittzell H (1999) Good genes, oxidative stress and condition-dependent sexual signals. Proc R Soc Lond B Biol Sci 266:1-12

Wedekind C (1992) Detailed information about parasites revealed by sexual ornamentation. Proc R Soc Lond B Biol Sci 247:169-174

Wedekind C, Folstad I (1994) Adaptive or nonadaptive immunosuppression by sex hormones? Am Nat 143:936-938

Wegmann TG, Smithies O (1966) A simple hemagglutination system requiring small amounts of red cells and antibodies. Transfusion 6:67-73

Westneat DF, Birkhead TR (1998) Alternative hypotheses linking the immune system and mate choice for good genes. Proc R Soc Lond B Biol Sci 265:1065-1073

Wingfield JC, Hegner RE, Dufty AM, Ball GF (1990) The "challenge hypothesis"- theoretical implications for patterns of testosterone secretion, mating systems and breeding strategies. Am Nat 136:829-846 